Old Dominion University

ODU Digital Commons

Biological Sciences Faculty Publications

Biological Sciences

2012

\title{
Successful Genotyping of Microsatellites in the Woolly Mammoth
}

Yasuko Ishida

Alfred L. Roca

Stephen Fratpietro

Alex D. Greenwood

Old Dominion University

Follow this and additional works at: https://digitalcommons.odu.edu/biology_fac_pubs

Part of the Ecology and Evolutionary Biology Commons, Genetics Commons, and the Paleobiology Commons

\section{Repository Citation}

Ishida, Yasuko; Roca, Alfred L.; Fratpietro, Stephen; and Greenwood, Alex D., "Successful Genotyping of Microsatellites in the Woolly Mammoth" (2012). Biological Sciences Faculty Publications. 290.

https://digitalcommons.odu.edu/biology_fac_pubs/290

\section{Original Publication Citation}

Ishida, Y., Roca, A. L., Fratpietro, S., \& Greenwood, A. D. (2012). Successful genotyping of microsatellites in the woolly mammoth. Journal of Heredity, 103(3), 459-464. doi:10.1093/jhered/esr139

This Article is brought to you for free and open access by the Biological Sciences at ODU Digital Commons. It has been accepted for inclusion in Biological Sciences Faculty Publications by an authorized administrator of ODU Digital Commons. For more information, please contact digitalcommons@odu.edu. 


\title{
Successful Genotyping of Microsatellites in the Woolly Mammoth
}

\author{
Yasuko Ishida, Alfred L. Roca, Stephen Fratpietro, and Alex D. Greenwood
}

From the Department of Animal Sciences, University of Illinois at Urbana-Champaign, Urbana, IL (Ishida and Roca); The Institute for Genomic Biology, University of Illinois at Urbana-Champaign, Urbana, IL (Roca); the Paleo-DNA Laboratory, Lakehead University, Thunder Bay, Ontario, Canada (Fratpietro); the Department of Biological Sciences, Old Dominion University, Norfolk, VA 23529 (Greenwood); and the Leibniz Institute for Zoo and Wildlife Research, Berlin 10315, Germany (Greenwood).

Address correspondence to Alex D. Greenwood at the address above, or e-mail: greenwood@izw-berlin.de.

Genetic analyses using ancient DNA from Pleistocene and early Holocene fossils have largely relied on mitochondrial DNA (mtDNA) sequences. Among woolly mammoths, Mammuthus primigenius, mtDNA analyses have identified 2 distinct clades (I and II) that diverged I-2 Ma. Here, we establish that microsatellite markers can be effective on Pleistocene samples, successfully genotyping woolly mammoth specimens at 2 loci. Although significant differentiation at the 2 microsatellite loci was not detected between 16 clade I and 4 clade II woolly mammoths, our results demonstrate that the nuclear population structure of Pleistocene species can be examined using fast-evolving nuclear microsatellite markers.

Key words: ancient DNA, Mammuthus primigenius, short tandem repeats, speciation

Genetic studies employing ancient DNA have been conducted on Pleistocene fossils from a variety of species, including woolly mammoths (Barnes et al. 2007; Debruyne et al. 2008; Gilbert et al. 2008). While often highly informative, mitochondrial DNA (mtDNA) records the evolutionary history of only the maternal lineage, which may provide an incomplete picture for species in which dispersal differs substantially between males and females (Roca et al. 2005, 2007; Petit and Excoffier 2009). For example, among elephants, gene flow between core social groups (herds) is male mediated because females do not typically migrate between herds (Poole 1989; Nyakaana and Arctander 1999; Archie et al. 2008). Sex differences in dispersal and in the variance of reproductive success may be responsible for the dissimilar phylogeographic patterns sometimes detected between mtDNA and nuclear loci in elephants (Hoelzer 1997; Roca et al. 2005, 2007; Hedrick 2007; Petit and Excoffier 2009; Rohland et al. 2010; Ishida et al. 2011).

Analyses of mtDNA from large numbers of temporally and geographically diverse woolly mammoth fossils have demonstrated the presence of multiple mtDNA lineages (Barnes et al. 2007; Debruyne et al. 2008; Gilbert et al. 2008), with the most basal split occurring between mtDNA clades I and II, which diverged 1-2 Ma (Gilbert et al. 2008). The deep split detected in woolly mammoth mtDNA may reflect speciation events, migrations, habitat changes, or glacial cycles (Barnes et al. 2007; Debruyne et al. 2008; Gilbert et al. 2008; Miller et al. 2008). Alternatively, because the social structure of woolly mammoths was likely similar to that of extant African elephants (Haynes 1991), the deeply divergent clades of mammoth mtDNA may be consequent to sex differences in dispersal and in the variance of reproductive success, believed responsible for the dissimilar phylogeographic patterns detected for mtDNA and nuclear loci in African elephants (Hoelzer 1997; Hedrick 2007; Rohland et al. 2010; Enk et al. 2011; Ishida et al. 2011).

The use of nuclear DNA markers can provide a more complete picture of population structure among elephants than the use of mtDNA alone (Ishida et al. 2011). Unlike mtDNA, nuclear genetic patterns reflect the contributions of maternal and paternal lineages. Nuclear markers, such as microsatellites, have been developed for extant elephants. To examine their utility in woolly mammoths, we tested elephant microsatellite markers on woolly mammoths. We successfully genotyped 20 woolly mammoths at 2 short tandem repeat (STR) loci, and compared microsatellite patterns between specimens belonging to each of the 2 highly divergent mammoth $\mathrm{mtDNA}$ clades, to determine whether microsatellite loci support the separation of mammoths into divergent groups concordant with the deep separation detected using mtDNA.

\section{Materials and Methods}

Mammoth Samples and Ancient DNA Extraction

Woolly mammoth samples were kindly provided by 3 collections. Mammoths provided by the American Museum of Natural History were from Alaska, the Taimyr Peninsula (Russia), and Wrangel Island (Russia) and were designated AMNH, AMNH_Tai, and AMNH_WRA, respectively. 
Table I Mammoth sample information

\begin{tabular}{|c|c|c|c|}
\hline Museum number & Locality and sample type & $\mathrm{Age}^{a}$ & Sample provider ${ }^{b}$ \\
\hline AMNH493 & Alaska, locality unkown, dentin & NA & $\mathrm{RM}$ \\
\hline AMNH8460 & Engineer Creek, Alaska, dentin & $13775 \pm 145 \mathrm{bp}$ & $\mathrm{RM}$ \\
\hline AMNH_JARKOV & Lake Taimyr & $20380 \pm 140 \mathrm{bp}$ & $\mathrm{RM}$ \\
\hline AMNH_RM103 & Lake Taimyr & NA & $\mathrm{RM}$ \\
\hline AMNH_RM23 & Lake Taimyr & NA & $\mathrm{RM}$ \\
\hline AMNH_RM24 & "Hook" mammoth, Kruchok, $r$ humerus & $20550 \pm 70 \mathrm{bp}$ & $\mathrm{RM}$ \\
\hline AMNH_RM27 & Pilot Site, Arilakh, 1 humerus & $43130 \pm 1280 \mathrm{bp}$ & $\mathrm{RM}$ \\
\hline AMNH_RM4 & L. Taimyr, Baskura Peninsula, $r$ humerus & $26080 \pm 170 \mathrm{bp}$ & $\mathrm{RM}$ \\
\hline AMNH_WRA_SP5 & Wrangel Island & NA & $\mathrm{RM}$ \\
\hline AMNH_WRA_SP6 & Wrangel Island & $4590 \pm 50 \mathrm{bp}$ & $\mathrm{RM}$ \\
\hline WMM_BOE1 & Bolshoy Lyakhovsky Island, mandible & NA & GB \\
\hline WMM_BOE4 & Kolyma River, skull & Kargin interglacial & GB \\
\hline WMM_BOE5 & Alazeya River, mandible & NA & GB \\
\hline WMM_BOE7 & Indigirka River basin, skull & NA & GB \\
\hline WMM_BOE10 & Adycha River, Ulakhan Sullar, rib & NA & GB \\
\hline WMM_BOE16 & Indigirka River basin, tooth fragment & $11-13000$ & GB \\
\hline WMM_BOE20 & Vilyui River, Namskeya Terasa, mandible & $\mathrm{NA}$ & GB \\
\hline PI_DUB1835 & NA & NA & ID \\
\hline PI_DUB3067 & NA & NA & ID \\
\hline PI_yakutia & NA & NA & ID \\
\hline
\end{tabular}

${ }^{a}$ NA indicates locality or dating data not available.

${ }^{b}$ RM: Ross DE MacPhee, American Museum of Natural History; GB: Gennady Boeskorov, Mammoth Museum, Yakutsk; and ID: Irena Dubrovo, Paleontological Institute, Moscow.

Samples provided by the World Mammoth Museum in Yakutsk were designated WMM; samples from the Paleontological Institute, Moscow were designated PI. Localities and known ages of samples are listed in Table 1. Ancient DNA extractions of the samples and all preamplification work were performed in the Paleo-DNA Laboratory, an accredited forensics "Clean Lab" at Thunder Bay, Canada, dedicated to research using ancient and degraded DNA. We followed procedures established for ancient DNA (Greenwood and Paabo 1999; Paabo et al. 2004; Willerslev and Cooper 2005; Roca et al. 2009), as detailed in Supplementary Data.

\section{PCR Amplification and Sequencing}

For STR loci, PCR primers were tagged for fluorescence detection (Boutin-Ganache et al. 2001). PCR amplification used a touchdown protocol (see Supplementary Data). Microsatellite products were separated on an Applied Biosystems (ABI) 3100 Genetic Analyzer using a GeneScan-350 ROX size standard (ABI) and Hi-Di Formamide (ABI). Results were analyzed with GeneMapper ID v3.2 (ABI). For 7 of the mammoth samples, microsatellite scoring was conducted independently by 2 workers (Y.I. and S.F.) with identical outcomes.

To improve amplification success rate with ancient DNA, we tested 8 primer pairs designed to produce shorter amplicon sizes at microsatellite loci (Ishida et al. forthcoming). These had been developed to improve amplification success for DNA extracted from African elephant dung samples (and were named by adding "s" for "short" to the end of the original locus designation). Only 2, FH60s and MS04s, worked consistently among mammoth samples, the others either failing to amplify or working on only few samples. In African elephants, these 2 loci are not in linkage disequilibrium (Comstock et al. 2002). Mammoth microsatellites FH60s and MS04s were sequenced to confirm the identity of the locus for samples WMM_BOE16 and WMM_BOE10.

For mtDNA, PCR used forward primer $5^{\prime}$-GCTCTACAAGCAATACT'T'TATAATCG-3' and reverse primer 5' AAATTGGGCTGAT'T'T'TCCTG-3'. The PCR and sequencing reactions for woolly mammoth DNA followed previously established procedures (Greenwood and Paabo 1999; Roca et al. 2009), with details included as Supplementary Data. Sequences of mtDNA and of microsatellites were too short to deposit in Genbank and can also be found in the Supplementary Data.

\section{Phylogenetic Analyses}

Mitochondrial sequence data were aligned using ClustalX version 2.0 (http://www.clustal.org/) (Larkin et al. 2007), and alignments were inspected visually. Phylogenetic relationships among mtDNA haplotypes were assessed using 4 approaches implemented in PAUP* $4.0 \mathrm{~b} 10$ (Altivec) (Swofford 2002), as detailed in Supplementary Data.

\section{Statistical Analyses}

Genetic diversity was estimated using the Excel microsatellite toolkit (http://animalgenomics.ucd.ie/sdepark/mstoolkit/) (Park 2001) and ARLEQUIN 3.1.1 (Excoffier and Lischer 2010). Population differentiation between clade I and clade II mammoth microsatellite alleles for each locus and across 2 loci was tested by Fisher's exact probability test based on 1000 steps in Markov chain algorithms in GENEPOP (http://genepop.curtin.edu.au/) (Rousset 2008). Exact tests of Hardy-Weinberg equilibrium using a Markov 


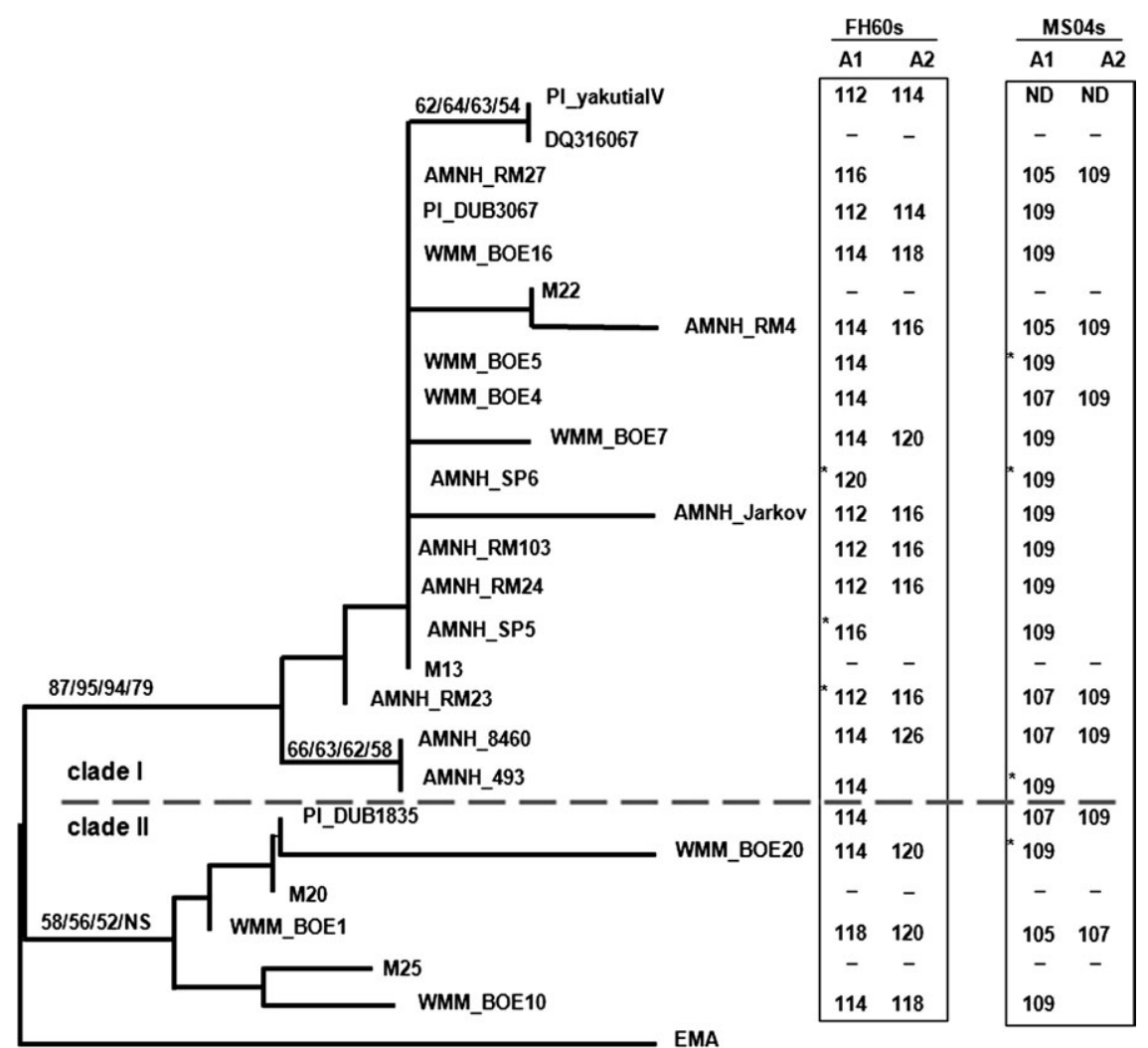

Figure I. Mitochondrial and nuclear analyses of mammoth samples. Left panel shows a phylogenetic tree inferred using 60 bp of the mitochondrial NADH dehydrogenase subunit 4 (NADH4) sequenced from 20 mammoth samples, along with sequences from GenBank (M13, M20, M22, and M25) (Gilbert et al. 2008); clade I and clade II mtDNAs were identified. The tree was rooted with an Asian elephant sequence (GenBank accession AJ428946) designated EMA. The neighbor joining (NJ) tree is shown, with bootstrap values for (left to right) maximum parsimony, NJ, minimum evolution, and maximum likelihood methods; NS indicates not supported. Right panel shows allele sizes at 2 microsatellite loci, FH60s and MS04s, corresponding to each mammoth listed directly to the left in the phylogeny. One allele size (A1) is listed for homozygotes; 2 allele sizes (A1 and A2) are listed for heterozygotes. Genotypes for which the number of successful replications was less than the minimum recommended $(3$ for heterozygotes and 4 for homozygotes) are indicated by an asterisk $\left(^{*}\right)$; ND indicates that alleles were not detected.

chain (forecasted chain length: 1000 000) were performed with ARLEQUIN 3.1 .1 (Excoffier and Lischer 2010). $F_{\text {st }}$ between clade I and clade II mammoths was estimated using microsatellite data in GENEPOP (http://genepop.curtin. edu.au/) (Rousset 2008).

\section{Results}

Two primer pairs (FH60s and MSO4s; the latter renamed from the African elephant microsatellite LafMS04) (Nyakaana and Arctander 1998; Fernando et al. 2001) yielded results across our 20 mammoth samples which, compared with other tested microsatellite markers (see Supplementary Data), were consistent, unambiguous, and polymorphic. An example of the microsatellite profile of mammoth DNA for FH60s and MS04s is shown in Supplementary Figure 1. The identity of the 2 loci in mammoths was confirmed by sequencing. Heterozygotes could be identified when both alleles were present in one PCR or when single alleles of different sizes were amplified in separate PCR replicates. Allelic dropouts were calculated as the proportion of PCRs on identified heterozygotes that amplified only 1 of the 2 alleles (Allentoft et al. 2011). Calculated allelic dropout ratios were 0.59 for FH60s and 0.47 for MS04s. This is high but comparable to the dropout rates of $0.36-0.70$ (average 0.53 ) observed for microsatellite loci in the most analogous previous ancient DNA study, conducted on moa specimens (Allentoft et al. 2011). For FH60s and MS04s, we attempted to confirm heterozygosity among mammoths by scoring the results of 3 independent PCR amplifications. Homozygotes were confirmed using at least 4 independent amplifications, as has been previously suggested for forensic and ancient DNA (Allentoft et al. 2011). Successful amplifications for each sample ranged from 3 to 8 (average 5.55) for FH60s and from 2 to 9 (average 5.47) for MSO4s.

For microsatellite FH60s, 13 of 20 mammoths were heterozygous and a total of 6 alleles were detected across the 
Table 2 Observed $\left(H_{\mathrm{o}}\right)$ and expected $\left(H_{\mathrm{e}}\right)$ heterozygosity at 2 microsatellite loci in mammoths

\begin{tabular}{|c|c|c|c|c|c|c|}
\hline Locus & $H_{\circ}$ & $\begin{array}{l}\text { Clade } \\
\text { I } \\
(\mathrm{Ho})\end{array}$ & $\begin{array}{l}\text { Clade } \\
\text { II } \\
\left(H_{\circ}\right)\end{array}$ & $H_{e}$ & $\begin{array}{l}\text { Clade } \\
\text { I } \\
\left(H_{e}\right)\end{array}$ & $\begin{array}{l}\text { Clade } \\
\text { II } \\
\left(H_{\mathrm{e}}\right) \\
\end{array}$ \\
\hline FH60s & 0.65 & 0.63 & 0.75 & 0.76 & 0.76 & 0.71 \\
\hline MS04s & 0.37 & 0.33 & 0.50 & 0.36 & 0.30 & 0.61 \\
\hline
\end{tabular}

mammoths (Figure 1). Allele sizes $(112,114,116,118,120$, and 126) were largely consistent with stepwise mutation of a 2-bp repeat. For MS04s, among 19 successful samples, 7 individuals were heterozygous and a total of 3 alleles were identified. Allele sizes (105, 107, and 109) were consistent with stepwise mutation of a 2-bp repeat. As would be expected, rare alleles were not found to be homozygous: For locus FH60s, only the 2 most common alleles, 114 and 116, were homozygous in any mammoths; for locus MS04s, the relatively rarer alleles 105 and 107 were detected only as heterozygotes.

We established that the specimens used for microsatellite genotyping (below) include 16 clade I and 4 clade II mammoths (Barnes et al. 2007; Debruyne et al. 2008; Gilbert et al. 2008) (Figure 1). For the 2 microsatellite loci, levels of observed and expected heterozygosity were similar whether within-clade or across all mammoths (Table 2). Both loci were found to be in Hardy-Weinberg equilibrium when all samples were included $(P>0.05)$; this result is notable because specimens from even a single locale could reflect allele changes that can occur locally over long spans of time. Although the data were limited to variation at only 2 microsatellite loci across 20 individuals, we looked for evidence of nuclear differentiation between mammoths carrying clade I and those with clade II mtDNA. For both loci, alleles observed among the 4 clade II mammoths were also found in clade I mammoths (Figure 2). $F_{\text {st }}$ values between clade I and clade II mammoths did not support strong differentiation at either nuclear locus: $F_{\text {st }}$ was 0.043 for FH60s, 0.019 for MS04s, and 0.036 for the 2 loci combined. For MS04s, the distribution of alleles was similar across mammoths in the 2 clades (Figure 2), and differentiation between the clades was not statistically supported (Fisher's exact test, $P=0.616$ ). For FH60s, the distribution of microsatellite alleles across mammoths in the $2 \mathrm{mtDNA}$ clades (Figure 2) appeared to be somewhat less similar than for MS04s, although differentiation between the clades did not reach statistical significance for FH60s $(P=0.052)$. The combined loci did not demonstrate differentiation $(P=$ 0.142 ), and additional STR genotyping would be required to reach strong conclusions about woolly mammoth nuclear genetic differentiation (Koskinen et al. 2004).

\section{Discussion}

Although microsatellites have been characterized in extinct animals, such as moas (Allentoft et al. 2009, 2011), this is the first attempt to our knowledge at microsatellite analysis on a collection of Pleistocene fossils. We demonstrated that microsatellite genotyping methods can be modified to accommodate Pleistocene fossils across time spans comparable to those for which $\mathrm{mtDNA}$ diversity can be examined. Only two microsatellite markers out of a larger set tested (see Supplementary Data) worked consistently in this study. This is similar to results reported for moa microsatellites: of 89 primer pairs tested in moas (including some developed in related species), only 5 loci proved effective for genotyping (Allentoft et al. 2011).

With highly degraded Pleistocene DNA, nuclear amplicon lengths must be limited. Allelic dropout may be especially high in ancient DNA due not only to selective amplification of short alleles (Wattier et al. 1998) but also to stochastic effects in which the low copy number of DNA can lead to only one of the alleles in a heterozygote being randomly amplified in the earlier steps of PCR (Taberlet
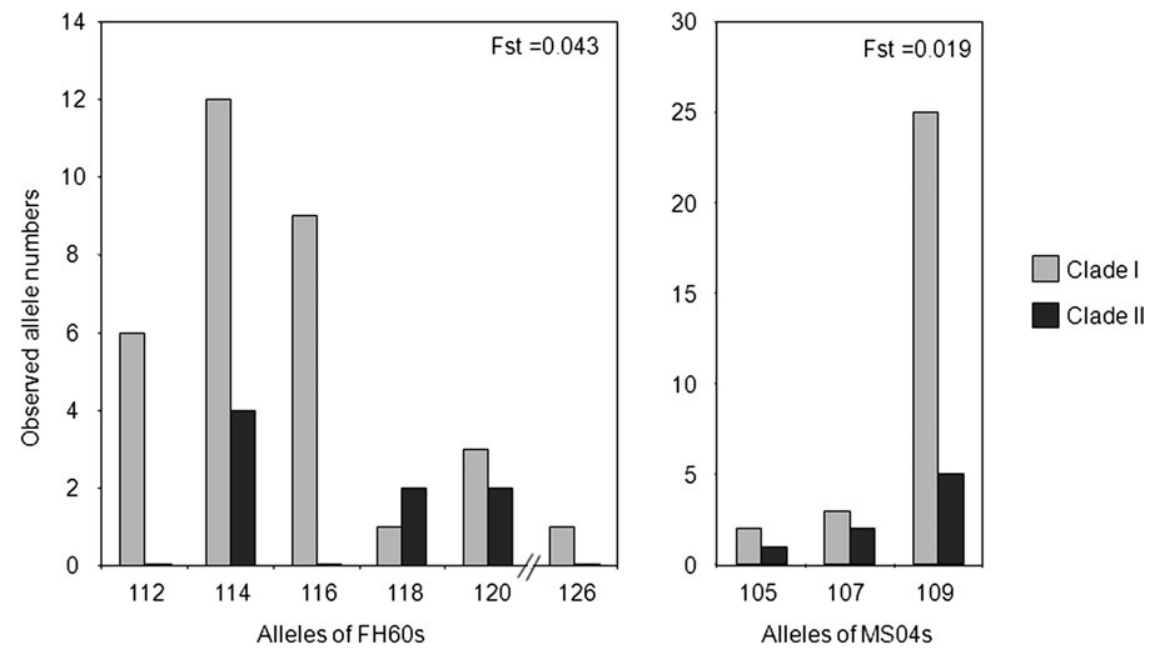

Figure 2. Allelic counts at 2 microsatellite loci in woolly mammoths. Totals are for mammoths carrying mtDNA clade I (light shading) or clade II (dark shading), with $F_{\text {st }}$ between clade I and clade II mammoths indicated for each locus. 
et al. 1996). For the 2 successful microsatellite loci, calculated dropout rates were high, 0.59 and 0.47 for microsatellite loci FH60s and MS04s, respectively, emphasizing the requirement for replicate PCRs to accurately genotype samples. After several replicates, mammoths were successfully genotyped and revealed substantial heterozygosity, in line with expected values (Table 2).

The distinctive mammoth mtDNA clades uncovered by previous studies may at least in part reflect the matrilocal and matrilineal structure of elephantid social groups (Roca et al. 2005, 2007; Enk et al. 2011). We found that mammoth genotypes at 2 microsatellite loci did not reveal significant differentiation between clade I and clade II mammoths, although any conclusion must be qualified because the data set was comprised of 2 loci and the sample size for Clade II mammoths was limited. Our results nonetheless demonstrate that it is possible to generate a more complete picture of population structure for Pleistocene species using fastevolving nuclear microsatellite markers.

\section{Supplementary Material}

Supplementary material can be found at http://www.jhered. oxfordjournals.org/.

\section{Funding}

Thomas F. and Kate Miller Jeffress Memorial Trust (J-855).

\section{Acknowledgments}

The authors wish to thank Michele Tisdale and Shannon Hensley for laboratory support. We thank Ross MacPhee of the American Museum of Natural History; Gennady Boeskorov of the Institute for Diamond and Precious Metals Geology, Siberian Branch of Russian Academy of Sciences, Yakutsk; and Irina Dubrovo of the Paleontological Institute, Moscow, for providing mammoth samples and information about dates and localities.

\section{References}

Allentoft ME, Oskam C, Houston J, Hale ML, Gilbert MT, Rasmussen M, Spencer P, Jacomb C, Willerslev E, Holdaway RN, et al. 2011. Profiling the dead: generating microsatellite data from fossil bones of extinct megafauna—protocols, problems, and prospects. PLoS One. 6(1):e16670.

Allentoft ME, Schuster SC, Holdaway R, Hale M, Mclay E, Oskam C, Gilbert MT, Spencer P, Willerslev E, Bunce M. 2009. Identification of microsatellites from an extinct moa species using high-throughput (454) sequence data. Biotechniques. 46(3):195-200.

Archie EA, Maldonado JE, Hollister-Smith JA, Poole JH, Moss CJ, Fleischer RC, Alberts SC. 2008. Fine-scale population genetic structure in a fission-fusion society. Mol Ecol. 17(11):2666-2679.

Barnes I, Shapiro B, Lister A, Kuznetsova T, Sher A, Guthrie D, Thomas MG. 2007. Genetic structure and extinction of the woolly mammoth, Mammuthus primigenius. Curr Biol. 17(12):1072-1075.

Boutin-Ganache I, Raposo M, Raymond M, Deschepper CF. 2001. M13-tailed primers improve the readability and usability of microsatellite analyses performed with two different allele-sizing methods. Biotechniques. 31(1):24-26, 28 .

Comstock KE, Georgiadis N, Pecon-Slattery J, Roca AL, Ostrander EA, O'brien SJ, Wasser SK. 2002. Patterns of molecular genetic variation among African elephant populations. Mol Ecol. 11(12):2489-2498.

Debruyne R, Chu G, King CE, Bos K, Kuch M, Schwarz C, Szpak P, Grocke DR, Matheus P, Zazula G, et al. 2008. Out of America: ancient DNA evidence for a new world origin of late quaternary woolly mammoths. Curr Biol. 18(17):1320-1326.

Enk J, Devault A, Debruyne R, King CE, Treangen T, O'rourke D, Salzberg SL, Fisher D, Macphee R, Poinar H. 2011. Complete Columbian mammoth mitogenome suggests interbreeding with woolly mammoths. Genome Biol. 12(5):R51.

Excoffier L, Lischer HE. 2010. Arlequin suite ver 3.5: a new series of programs to perform population genetics analyses under Linux and Windows. Mol Ecol Resour. 10(3):564-567.

Fernando PJ, Vidya TNC, Melnick DJ. 2001. Isolation and characterization of tri- and tetranucleotide microsatellite loci in the Asian elephant, Elephas maximus. Mol Ecol Notes. 1(4):232-233.

Gilbert MT, Drautz DI, Lesk AM, Ho SY, Qi J, Ratan A, Hsu CH, Sher A, Dalen L, Gotherstrom A, et al. 2008. Intraspecific phylogenetic analysis of Siberian woolly mammoths using complete mitochondrial genomes. Proc Natl Acad Sci U S A. 105(24):8327-8332.

Greenwood AD, Paabo S. 1999. Nuclear insertion sequences of mitochondrial DNA predominate in hair but not in blood of elephants. Mol Ecol. 8(1):133-137.

Haynes G. 1991. Mammoths, mastodonts, and elephants: biology, behavior, and the fossil record. Cambridge: Cambridge University Press.

Hedrick PW. 2007. Sex: differences in mutation, recombination, selection, gene flow, and genetic drift. Evolution. 61(12):2750-2771.

Hoelzer GA. 1997. Inferring phylogenies from mtDNA variation: mitochondrial-gene trees versus nuclear-gene trees revisited. Evolution. 51(2):622-626.

Ishida Y, Demeke Y, De Groot PJVC, Georgiadis NJ, Leggett K, Fox VE, Roca AL. Forthcoming. Short amplicon microsatellite markers for low quality elephant DNA.

Ishida Y, Oleksyk TK, Georgiadis NJ, David VA, Zhao K, Stephens RM, Kolokotronis SO, Roca AL. 2011. Reconciling apparent conflicts between mitochondrial and nuclear phylogenies in African elephants. PLoS One. 6(6):e20642.

Koskinen MT, Hirvonen H, Landry PA, Primmer CR. 2004. The benefits of increasing the number of microsatellites utilized in genetic population studies: an empirical perspective. Hereditas. 141(1):61-67.

Larkin MA, Blackshields G, Brown NP, Chenna R, Mcgettigan PA, Mcwilliam H, Valentin F, Wallace IM, Wilm A, Lopez R, et al. 2007. Clustal W and clustal X version 2.0. Bioinformatics. 23:2947-2948.

Miller W, Drautz DI, Ratan A, Pusey B, Qi J, Lesk AM, Tomsho LP, Packard MD, Zhao F, Sher A, et al. 2008. Sequencing the nuclear genome of the extinct woolly mammoth. Nature. 456(7220):387-390.

Nyakaana S, Arctander P. 1998. Isolation and characterization of microsatellite loci in the African elephant, Loxodonta africana. Mol Ecol. 7(10):1436-1437.

Nyakaana S, Arctander P. 1999. Population genetic structure of the African elephant in Uganda based on variation at mitochondrial and nuclear loci: evidence for male-biased gene flow. Mol Ecol. 8(7):1105-1115.

Paabo S, Poinar H, Serre D, Jaenicke-Despres V, Hebler J, Rohland N, Kuch M, Krause J, Vigilant L, Hofreiter M. 2004. Genetic analyses from ancient DNA. Annu Rev Genet. 38:645-679.

Park SDE. 2001. Trypanotolerance in West African cattle and the population genetic effects of selection [PhD thesis]. [Dublin (Ireland)]: University of Dublin.

Petit RJ, Excoffier L. 2009. Gene flow and species delimitation. Trends Ecol Evol. 24(7):386-393. 
Poole JH. 1989. Mate guarding, reproductive success and female choice in African elephants. Anim Behav. 37:842-849.

Roca AL, Georgiadis N, O'brien SJ. 2005. Cytonuclear genomic dissociation in African elephant species. Nat Genet. 37(1):96-100.

Roca AL, Georgiadis N, O’brien SJ. 2007. Cyto-nuclear genomic dissociation and the African elephant species question. Quat Int. 169-170:4-16.

Roca AL, Ishida Y, Nikolaidis N, Kolokotronis SO, Fratpietro S, Stewardson K, Hensley S, Tisdale M, Boeskorov G, Greenwood AD. 2009. Genetic variation at hair length candidate genes in elephants and the extinct woolly mammoth. BMC Evol Biol. 9:232.

Rohland N, Reich D, Mallick S, Meyer M, Green RE, Georgiadis NJ, Roca AL, Hofreiter M. 2010. Genomic DNA sequences from mastodon and woolly mammoth reveal deep speciation of forest and savanna elephants. PLoS Biol. 8(12):e1000564.

Rousset F. 2008. GENEPOP'007: a complete re-implementation of the GENEPOP software for Windows and Linux. Mol Ecol Resour. 8(1):103-106.
Swofford DL. 2002. PAUP*: phylogenetic analysis using parsimony (*and other methods). Version 4.0b10. Sunderland (MA): Sinauer.

Taberlet P, Griffin S, Goossens B, Questiau S, Manceau V, Escaravage N, Waits LP, Bouvet J. 1996. Reliable genotyping of samples with very low DNA quantities using PCR. Nucleic Acids Res. 24(16):3189-3194.

Wattier R, Engel CR, Saumitou-Laprade P, Valero M. 1998. Short allele dominance as a source of heterozygote deficiency at microsatellite loci: experimental evidence at the dinucleotide locus Gv1CT in Gracilaria gracilis (Rhodophyta). Mol Ecol. 7(11):1569-1573.

Willerslev E, Cooper A. 2005. Ancient DNA. Proc R Soc B Biol Sci. 272(1558):3-16.

Received September I5, 20 I I; Revised November I, 20I I; Accepted November 16, 2011

\section{Corresponding Editor: William Murphy}

